\title{
Alice in Wonderland syndrome as an initial manifestation of Epstein-Barr virus infection
}

\author{
M Cinbis, S Aysun
}

\begin{abstract}
We present a patient with serologically confirmed Epstein-Barr virus (EBV) infection who had illusions of size, shape, and colour of objects but none of the typical symptoms and signs peculiar to infectious mononucleosis (IM) except sore throat which developed 2 weeks after the initial visual disturbances. The bizarre feelings about the images of body and objects are called the 'Alice in Wonderland syndrome' due to the similarity with Alice's dreams. The same symptomatology including visual metamorphosia is defined in patients with migraine, epilepsy, intoxication due to hallucinogenic drugs, schizophrenia, hyperpyrexia, and cerebral lesions. Alice in Wonderland syndrome has also been reported in the course of IM.
\end{abstract}

\section{Case report}

A 7-year-old girl complained of seeing objects smaller and in different colours than they were, such as seeing her mother's head green and smaller in comparison with her body. These metamorphoses were intermittent lasting a few minutes. She was first examined by an ophthalmologist whose examination including colour vision was completely normal. Neither visual agnosia nor nominal dysphasia was a complaint. However the patient was never examined during an attack, each of which lasted a few minutes. It was thought that she was faking. Her complaints continued and she was admitted to Hacettepe Children's Hospital. Her physical and neurological examinations were normal. Laboratory investigations included a normal brain scan and minimal irregularity of background activity over the posterior areas of the EEG. Estimations of antibodies of types IgG and IgM for EBV were positive by enzymatic immunoassay. The level of IgG antibodies in our patient was 1.2 and that of IgM antibodies was $2 \cdot 8$. During the follow-up period lasting 5 months no other complication occurred and visual symptoms recovered spontaneously. She has been completely normal for 6 months.

There was no personal or family history of epilepsy, migraine, or drug use. The only remarkable information about the family was that her father had had a serologically confirmed hepatitis A infection but our patient was seronegative for HAV.

Department of
Pediatric Neurology, Hacettepe Children's Hospital, Hacettepe University, Faculty of Medicine, Turkey $M$ Cinbis S Aysun

Correspondence to Professor S Aysun.

Accepted for publication 3 October 1991

\section{Discussion}

Various neurological and psychological manifestations may occur during or after IM..$^{1-4}$ These include meningoencephalitis, encephalitis, the Guillain-Barré syndrome, mononeuritis, personality changes such as irritability, emotion- ality, asocial behaviour, destructiveness, depression and anxiety, benign recurrent aseptic meningitis (Mollaret's meningitis), inappropriate antidiuretic hormone secretion, myalgic encephalomyelitis syndrome, acute transverse myelopathy, acute cerebellar ataxia, convulsions, and retinochoroiditis..$^{5-14}$

One of the perceptual disturbances in IM is the Alice in Wonderland syndrome. A few cases have been reported after Copperman's first report. Visual metamorphosia was described in patients reported by Copperman ${ }^{1}$ as a presenting symptom, but it was realised during the examination that there were other signs suggesting IM, such as generalised lymphadenopathy, splenomegaly, and rash. On the other hand in the patient reported by Sanguineti ${ }^{2}$ the length of time elapsing between the initiation of visual symptoms and the development of signs suggesting IM is not known accurately. Since this patient was examined by an ophthalmologist initially it is not known whether she had these other clinical signs at that time. Subsequently Eshel $e t a l^{3}$ and Lahat ${ }^{4}$ reported two patients with the Alice in Wonderland syndrome which developed after IM.

It is easy to recognise this in a patient with full blown features of IM but this is not so if the visual disturbances preceded the classic symptoms of IM or if IM follows a subclinical course. When our patient suffered from micropsia there was no other sign suggesting IM.

This patient is another example of the extensive variation of the presenting symptoms of IM reminding us to keep the Alice in Wonderland syndrome in mind in patients with visual illusions but no other symptoms.

1 Copperman SM. Alice in Wonderland syndrome as a presenting symptom of infectious mononucleousis in children Clin Pediatr (Phil) 1977; 16: 143-6.

2 Sanguineti G. Alice in Wonderland syndrome in a patient with infectious mononucleosis. F Infect Dis 1983; 147: 782.

infectious mononucleosis. F Infect Dis 1983; 147: 782. tion of acute Epstein-Barr virus infection. Pediatr Infect D tion of acute

4 Lahat $\mathrm{E}$, et al. Alice in Wonderland syndrome and infectious mononucleosis in children. $\mathcal{F}$ Neur Neurosur Psych 1990; 53 : 1104 .

5 Todd J. The syndrome of Alice in Wonderland. Can Med Ass $\mathcal{F}$ 1955; 73: 701-4.

6 Hendler N, Leahy W. Psychiatric and neurologic sequelae of infectious mononucleosis. Am $\mathcal{F}$ Psychiat 1978; 135: 842-4.

7 Graman PS. Mollaret's meningitis associated with acute Epstein-Barr virus mononucleosis. Arch Neurol 1987; 44: Epstein-Ba.

8 Murdoch JC. The myalgic encephalomyelitis syndrome NZ Med F 1989; 372-3.

9 Shepherd C. Myalgic encephalomyelitis. Practitioner 1989, 233: 41-6.

10 Silber MH. Acute transverse myelopathy in Epstein-Barr virus infection. S A Med J 1983; 64: 753-4. of mononucleosis. Ind Med 1990: 190-191.
isher DM, Foley sequela

12 Wadhwa NK, Ghose RR. Acute cerebellar ataxia and in fectious mononucleosis. Postgrad Med F 1983; 59: 457-8.

13 Mohanaruban K, Fisher DJH. A combination of cranial and peripheral nerve palsies in infectious mononucleosis. Postperipheral nerve palsies in in

14 Mouallem M, Friedman E, Rubinstein E. Inappropriate antidiuretic hormone secretion with Infectious Mononucleosis. $N$ Engl F Med 1984; July: 262. 